\title{
Genetic Strategies for Probing Conscientiousness and Its Relationship to Aging
}

\author{
Susan C. South \\ Purdue University
}

\author{
Robert F. Krueger \\ University of Minnesota-Twin Cities
}

\begin{abstract}
Conscientiousness is an important trait for understanding healthy aging. The present article addresses how behavioral and molecular genetics methodologies can aid in furthering explicating the link between conscientiousness and aspects of health and well-being in later life. We review the etiology of conscientiousness documented by both quantitative and molecular genetics methods. We also discuss the ways behavior genetics can be used to continue to help refine the concept of conscientiousness and to help identify points of etiological overlap between conscientiousness and healthy aging outcomes. Phenotypic research has established nontrivial associations between conscientiousness and important outcomes, but behavior genetic methods can determine what the causal (genetic and environmental) mechanisms are behind these relationships. An empirical example of one of these techniques is provided using twin data from the Midlife in the United States (MIDUS) study. We demonstrate that conscientiousness moderates genetic and environmental influences on problem alcohol use, such that greater levels of conscientiousness buffer against the random effects of the environment. Finally, suggestions for future work in this area are discussed.
\end{abstract}

Keywords: conscientiousness, aging, behavior genetics, twins, alcohol

Conscientiousness has strong phenotypic links to aspects of healthy aging, including physical and mental health conditions and behaviors associated with health outcomes. Still relatively unknown, though, are the mechanisms that explain these associations. Behavior genetic methods hold the potential for better understanding why conscientiousness is correlated with healthy aging by examining the complex interplay between genetic and environmental influences. In the present article, we examine what quantitative and molecular genetics methods can add to the study of conscientiousness in healthy aging. Instead of merely reviewing the field so far, we take a different approach. Specifically, we mix together a review of what has been done, an example of what can be done, and suggestions for what to do in the future. We begin with a summary of the present state of knowledge regarding genetic and environmental influences on conscientiousness. We then provide an empirical example of what is possible with newer behavior genetic models, which have the potential to elucidate how conscientiousness intersects with genetic and environmental influences on health outcomes. Finally, we conclude with our suggestions for how behavior genetic methods can be used for further

This article was published Online First November 26, 2012.

Susan C. South, Department of Psychological Sciences, Purdue University; Robert F. Krueger, Department of Psychology, University of Minnesota-Twin Cities.

This research was supported by the John D. and Catherine T. MacArthur Foundation Research Network on Successful Midlife Development and by National Institute on Aging Grant AG20166.

Correspondence concerning this article should be addressed to Susan C. South, Department of Psychological Sciences, Purdue University, 703 Third Street, West Lafayette, IN 47907. E-mail: ssouth@purdue.edu research into the mechanisms that explain connections between conscientiousness and healthy aging.

\section{Behavior Genetic Modeling of Conscientiousness}

\section{What We Know: Twin and Adoption Studies}

The finding that conscientiousness, like every other broad domain of personality, is influenced by both genes and the environment is the result of decades of work with biometric modeling of twin data. Classical twin models take advantage of the differences between identical (monozygotic; MZ) twins, which result from one fertilized egg splitting in two while in-utero and thus share $100 \%$ of their genes, and fraternal (dizygotic; DZ) twins, which result from two separate eggs being fertilized at the same time and thus share $50 \%$ of their segregating genes on average. By comparing the similarity between MZ twins and DZ twins reared together (i.e., when the degree of genetic and shared family environment is known), it is possible to decompose the variance in that phenotype into genetic and environmental components. Adoption studies have also been an important tool for behavior geneticists, and recent extended-family designs suggest new ways of thinking about the etiology of personality. We focus much of our discussion on extensions of the twin model and how these innovative models offer rich new opportunities to understand the complex interplay between conscientiousness and healthy aging.

Classical twin models make use of the differences between twin pairs to characterize the etiology of individual differences. An initial comparison of correlations within twin pairs across $\mathrm{MZ}$ and DZ twins will give a general estimate of the size of genetic and environmental influences. If genetic influences on a trait are present, then the MZ correlation is greater than the DZ correlation. If 
the variance in a trait is due completely to nonshared, environmental components, then the $\mathrm{MZ}$ and $\mathrm{DZ}$ correlations are both zero. This only gives a general indication of influences on a trait. Formal biometric modeling of twin data using structural modeling software (e.g., Mx; Neale, Boker, Xie, \& Maes, 2003b) fits models to the variances and covariances between $\mathrm{MZ}$ and $\mathrm{DZ}$ twin pairs on the phenotype. A basic univariate twin model (see Figure 1) separates the total variance in a phenotype within a population into three independent sources: additive genetic influences (abbreviated A), generally assumed to be many alleles of small effect size that sum together; the shared, or common environment (abbreviated $\mathrm{C}$ ), which can include similarity due to growing up in the same family or the similarity of the broader rearing environment (e.g., socioeconomic status [SES], neighborhood effects); and nonshared environment (abbreviated E), the experiences that are unique to members of the same family and that make them different from one another (Plomin, DeFries, McClearn, \& McGuffin, 2008). The total variance in a phenotype is the sum of the "ACE" influences, and the well-known heritability statistic $\left(h^{2}\right)$ is the proportion of variance accounted for by genetic influences (i.e., $\mathrm{A} /[\mathrm{A}+\mathrm{C}+\mathrm{E}])$.

We begin by briefly reviewing the voluminous body of literature on univariate twin analysis of conscientiousness-type constructs. Establishing the relative influences of genetic, shared, and nonshared effects on conscientiousness is not a trivial endeavor, and thus we spend some time on the findings and their importance. Although it may seem obvious to some, the demonstration of genetic influence on conscientiousness is vital for many types of subsequent behavior genetic modeling. If there was no evidence of any substantial genetic effects on conscientiousness, then it would, by definition, be impossible to examine (a) genetic overlap between conscientiousness and known external correlates (e.g., health outcomes), (b) the genetic structure of lower order conscientiousness trait facets, and (c) the change in genetic influences on conscientiousness across developmental stages, among other questions. Conversely, if research consistently found substantial shared environmental influences on conscientiousness, then this would have motivated research designed to understand why people are more similar within families than would be predicted by their genetic relationships; however, such influences have been routinely small for conscientiousness and related traits. Finally, the magnitude and nature of nonadditive genetic effects on conscientiousness have potentially important implications for present gene-hunting techniques, as they would suggest that these effects (e.g., Gene $\times$ Gene interactions) may be one reason why identifying specific molecular polymorphisms associated with conscientiousness and related phenotypes has been challenging.

The univariate twin model has been applied in various samples to estimate the components of variance for major domains of personality, including conscientiousness. Like the traits of neuroticism and extraversion, conscientiousness figures prominently in most major trait models of personality, including the five-factor model(FFM)/Big Five model (Goldberg, 1993; McCrae \& Costa, 2008), often measured by the NEO Personality Inventory-Revised (NEO-PI-R; Costa \& McCrae, 1992); the three-factor model of Eysenck (Eysenck, 1991; Eysenck \& Eysenck, 1975), assessed by the Eysenck Personality Questionnaire; Tellegen's big three model, as conceptualized in the Multidimensional Personality Questionnaire (MPQ; Tellegen \& Waller, in press), and the sevenfactor model of Cloninger's Temperament and Character Inventory (Cloninger, Svrakic, \& Przybeck, 1993). A recent factor analytic study found that different scales indexing conscientiousness-

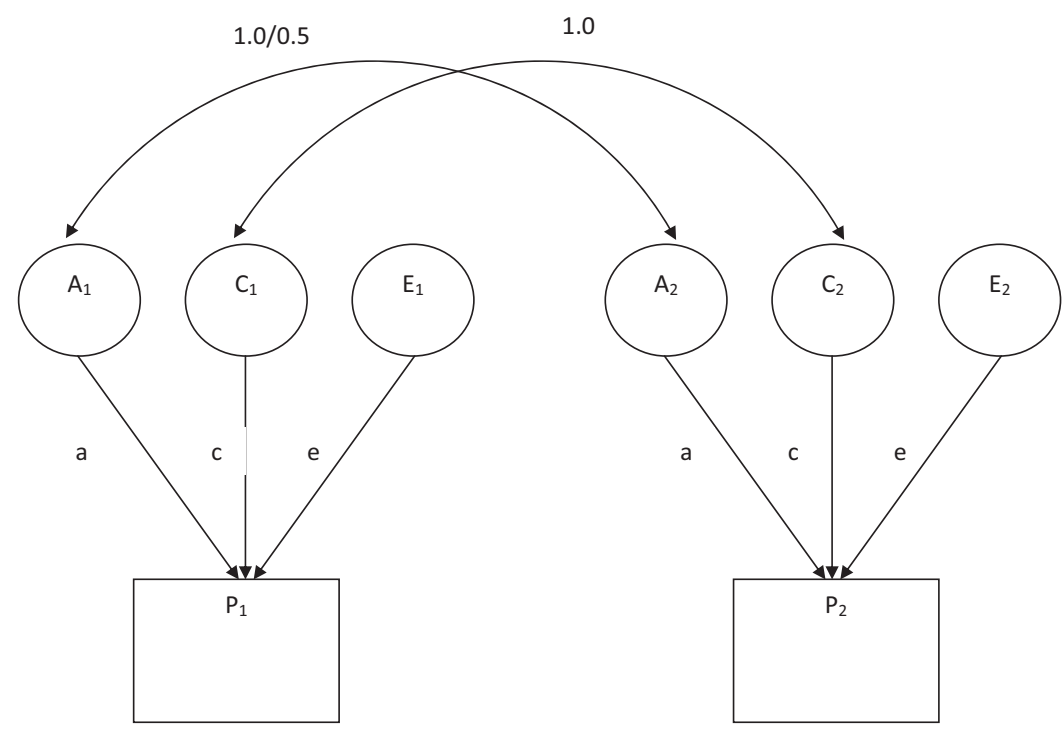

Figure 1. Univariate ACE model for the genetic and environmental decomposition of an observed variable (i.e., phenotype, $\mathrm{P})$. Model is shown with both members of the twin pair $\left(\mathrm{P}_{1}\right.$ and $\left.\mathrm{P}_{2}\right)$. Latent variables represent additive genetic influences $(\mathrm{A})$, common environmental influences shared between family members $(\mathrm{C})$, and nonshared environmental influences (E). Latent genetic influences are correlated 1.0 for monozygotic (MZ) twins and 0.5 for dizygotic (DZ) twins. Latent common environmental influences are correlated 1.0 for $\mathrm{MZ}$ and DZ twins. The total variance in $P$ is calculated by squaring and summing all paths leading to it: $a^{2}+c^{2}+e^{2}$. 
like traits from these different inventories tended to load together at the five-factor level (Markon, Krueger, \& Watson, 2005). The general point here is that many common measures of normal personality incorporate a "conscientiousness"-type domain, and many of these have been examined using behavior genetic methods. At this point, we can quite confidently conclude that genetic influences play a substantial role in the etiology of conscientiousness.

When examined as part of the FFM of personality, predominantly assessed using some version of the NEO-PI-R, the heritability of Conscientiousness is in the range of 38\%-53\%; the majority of the rest of the variance can be explained by nonshared environmental influences (Bouchard \& Loehlin, 2001). In the Swedish Adoption/Twin Study of Aging sample, Bergeman et al. (1993) found slightly lower estimates of heritability for Conscientiousness from the NEO-PI (29\%) as well as evidence of gender differences ( $41 \%$ for men, $11 \%$ for women). Genetic influences on lower order traits subsumed under the broad Conscientiousness domain also generally show moderate genetic influences (Jang, Livesley, Riemann, \& Vernon, 2002; Jang, Livesley, \& Vernon, 1996; Jang, McCrae, Angleitner, Riemann, \& Livesley, 1998; Yamagata et al., 2006). Heritability for Eysenck's Psychoticism domain (which refers to antisocial, unconscientious tendencies in Eysenck's conceptualization) across 15 studies was .46 (as cited in Bouchard \& Loehlin, 2001). Genetic influences for MPQ Constraint (and its subscales of Control, Harm Avoidance, and Traditionalism) account for roughly 50\% of the variance (Blonigen, Carlson, Hicks, Krueger, \& Iacono, 2008; Tellegen et al., 1988). Gender differences have been found on the MPQ Control subscale (lower broad sense heritability for women; Finkel \& McGue, 1997), although other studies report that genetic and environmental parameters can be held equivalent across men and women (Blonigen et al., 2008). The main point is that, taking a rough average across different samples (and different populations), ages, and measurement instruments, approximately half the variance in conscientiousness can be explained by genetic differences between people.

The findings from adoption studies, which are similar to the twin method in taking advantage of samples with known degrees of genetic relatedness to examine genetic and environmental influences, are often quite similar to findings from twin studies. In general, adoption studies also find little shared environmental effects and substantial unique environmental effects on personality (Bouchard \& Loehlin, 2001; Loehlin, Willerman, \& Horn, 1987; Plomin, Corley, Caspi, Fulker, \& DeFries, 1998). One way in which findings from twin and adoption studies often differ is that adoption studies will find heritability estimates of smaller magnitude. For instance, in the Colorado Adoption Project, Plomin et al. (1998) estimated heritabilities of .00 for emotionality, .20 for activity, .27 for sociability, and .07 for impulsivity among a sample of 16-year-old adolescents; shared environmental influences from parent to child were negligible for all traits. One explanation for the discrepancy is the presence of nonadditive genetic effects-when the effect of genes can depend on the presence of other genes, that is, dominant or epigenetic effects. The presence of nonadditive effects can result in higher heritability estimates in twin studies, because MZ twins share $100 \%$ of all genes, whereas DZ twins share approximately $50 \%$ of all additive genes but nonadditive genetic effects have lesser influence on their similarity. Behavior genetic modeling of twin data can test for dominance effects, and in fact some find evidence for dominance on Conscientiousness from the NEO (Bergeman et al., 1993) and Constraint from the MPQ (Finkel \& McGue, 1997; Tellegen et al., 1988); the difficulty with dominance effects in twin studies is that they cannot be modeled simultaneously with additive genetic, shared, and nonshared environmental effects, and they require relatively large samples to estimate accurately (Martin, Eaves, Kearsey, \& Davies, 1978).

Extended-family designs are not limited by the same methodological constraints and thus may be more useful for teasing out the presence of nonadditive genetic effects. There are now several studies that extend on both the basic twin- and adoption-family designs to take advantage of the unique composition of many contemporary families. Extensions of the twin design that incorporate additional siblings and even genetically unrelated children have found evidence of nonadditive genetic effects (Keller, Coventry, Heath, \& Martin, 2005; Loehlin, Neiderhiser, \& Reiss, 2003). Using a twin + sibling design, Luciano, Wainwright, Wright, and Martin (2006) found broad sense heritability (additive and nonadditive genetic influences) of the NEO Conscientiousness facets ranging from $18 \%$ (Order) to $49 \%$ (Self-Discipline), with dominance effects ranging from $7 \%$ (Order) to $49 \%$ (SelfDiscipline). Another study, the Minnesota Sibling Interaction and Behavior Study, includes a sample of families composed of parents and two adolescent siblings in which (a) all family members are biologically related, (b) there are two adopted siblings, or (c) there is one adopted sibling and one biological sibling (Buchanan, McGue, Keyes, \& Iacono, 2009). A recent report from this study found evidence of significant shared environmental influences (20\%) on MPQ Constraint. Of course, this may reflect the fact that the siblings are still relatively young and living together, and the influence of the shared environment may decrease as the twins age and move apart. Finding substantial estimates of the shared environment is important, however, given that behavior genetic modeling usually finds negligible estimates of the shared environment on personality traits including conscientiousness.

Lack of shared environmental effects is frequently misunderstood to imply that the rearing environment has no influence on variation in conscientiousness. This interpretation is incorrect because there are many other ways the rearing environment can impact development, beyond making people more similar within families than they already are for genetic reasons (i.e., beyond shared environmental effects). For example, as Eisenberg, Duckworth, Spinrad, and Valiente (2014) pointed out, each child within a family may have their own unique experience with each parent. A child's temperament and personality can affect the parent's reaction to and relationship with that child (a phenomenon known as gene-environment correlation, which we discuss further below), or relationships may change the magnitude of genetic or environmental effects on personality and its development (e.g., Krueger, South, Johnson, \& Iacono, 2008). Regardless, future studies that continue to use these extended-family designs will be an important method for understanding influences that have been traditionally difficult to identify in classical twin studies, including nonadditive genetic and shared family environmental effects. 


\section{The Etiological Structure of Conscientiousness}

Besides providing estimates of the genetic and environmental contributions to variation in conscientiousness, twin studies have also been used to determine whether the genotypic architecture underlying the structure of conscientiousness mirrors the phenotypic organization. That is, many major trait theories of personality that include a conscientiousness-type domain were built on factor analytic studies that parse the phenotypic variation into meaningful domains. The FFM, for instance, is theorized to represent basic biological tendencies that can account for all of the multivariate personality space (McCrae \& Costa, 2008). Factor analysis of the NEO-PI-R, the most widely used measure of the FFM, has been used to confirm that each of the five higher order domains is indicated by six lower order facet scales, as intended by the NEO's designers. Multivariate behavior genetic methods can be used to examine whether the phenotypic structure of personality, as represented by the FFM and other trait theories, is well replicated using genetically informative family data; if the genetic and environmental influences on the facets of NEO Conscientiousness reflect the phenotypic structure, then this would suggest that the FFM conceptualization and assessment instruments used to measure it are doing a good job of capturing nature as it truly exists.

For this type of modeling, the basic univariate twin model is extended to include two or more phenotypes. Then, the covariances between different phenotypes (here, facets of conscientiousness) are decomposed into the genetic and environmental influences that are unique to each and shared in common. Different models representing alternate theories of the genotypic structure of personality can then be compared. Jang et al. (2002) applied these multivariate models to the NEO-PI-R (Costa \& McCrae, 1992). Instead of finding a clear parallel between phenotypic and genotypic data, they found that conscientiousness required two genetic and two nonshared environmental factors. The authors posited that all of the FFM domains "do not exist as veridical psychological entities per se, but rather they exist as useful heuristic devices" (Jang et al., 2002, p. 99). A later study using a nationwide sample of American twins also found differences in the degree to which various adjectives posited to measure conscientiousness actually reflected the genetic variation in conscientiousness (Johnson \& Krueger, 2004). Unlike neuroticism and extraversion, which were well modeled by unitary latent factors that had genetic and environmental influences on those unitary factors, conscientiousness was best explained by a model that included a genetic factor and an environmental factor that influenced each of the observed traits used to measure the conscientiousness construct to differing degrees. The authors concluded that conscientiousness may therefore have a "loose" organizational structure as compared with neuroticism and extraversion. Another study, however, did conclude that the NEO-PI-R Conscientiousness facets reflect one, genetically robust domain (Yamagata et al., 2006). Krueger (2000) has applied models to twin data collected with the MPQ. Phenotypic research on the structure of the MPQ generally finds one higher order domain of Constraint indicated by lower order subscales of Control, Harm Avoidance, and Traditionalism. Using multivariate biometric modeling, Krueger found that the additive genetic structure of Constraint closely parallels the phenotypic structure (i.e., strong loadings on one factor with lesser cross-loadings), although the nonshared environmental structure of Constraint was indicated by different subscales (e.g., achievement and lack of aggression).

These somewhat contradictory findings emphasize the importance of assessment and measurement in our understanding of the concept of conscientiousness. In order to truly capture the nature of conscientiousness, it is necessary to measure the different facets, because different "parts" of the broader domain may reflect genetically differentiable processes. It may also be necessary to modify our present personality assessment methods in order to better identify an etiologically coherent consciousness construct. Research that uses multiple raters to examine the genetic and environmental influences on NEO-PI-R domains and facets finds a greater proportion of variance attributable to genetic influences than studies using single or multiple self-reports (Kandler, Riemann, Spinath, \& Angleitner, 2010). This phenomenon (estimates of greater heritability) may reflect a more accurate crosssituational phenotype, as the domain that is modeled better captures commonalities of behavior across different settings to which observers have access. It also suggests that future work could strive to modify and revise personality inventories, using data from multiple raters, to better capture "genetically crisp categories" (Farone, Tsuang, \& Tsuang, 1999).

\section{Longitudinal Structure of Conscientiousness}

We also have growing knowledge of how genetic and environmental influences on conscientiousness change over the course of the life span. Several twin studies have examined the etiological influences on conscientiousness at different developmental periods, which has obvious implications for understanding the association between conscientiousness and aging. If we wish to examine the interplay between conscientiousness and healthy aging, it is important to understand how the etiology of conscientiousness changes over time. Studies conducted to date generally find that stability of personality traits, including conscientiousness, over time is largely due to genetic influences, whereas change is largely explained by nonshared environmental influences; these studies have been conducted with data from average ages 17-24 (Blonigen et al., 2008), 23-35, 41-55 (Kandler, Bleidorn, et al., 2010a), and 20-30 (McGue, Bacon, \& Lykken, 1993). Of note, Blonigen et al. (2008) did find significant genetic contributions to change over time using the MPQ in a sample of twins measured from adolescence to early adulthood.

Two notable recent additions to this literature add a biometric component to longitudinal growth curve modeling, thus allowing for estimates of genetic and environmental influences on individual differences in stability and change of personality, which may not be a simple linear change. Using a German sample who completed a translated version of the NEO-PI-R three times over the course of 10 years, Bleidorn, Kandler, Riemann, Angleitner, and Spinath (2009) found that genetic effects on both stability (i.e., the intercept growth factor) and change (i.e., the slope growth factor) of the conscientiousness domain were higher than nonshared environmental effects, although there were interesting differences between facets within the domain (e.g., there were no significant genetic effects on the stability of the dutifulness and competence facets). This German study was limited, however, in that a relatively small sample of twins with a wide range in ages $(18-59, M$ at first assessment $=30.6, S D=9.15)$ was used. 
Recently, Hopwood and colleagues (2011) used three waves of data on the MPQ in the Minnesota Twin Family Study to examine genetic and environmental influences on personality trait stability and growth from adolescence to adulthood (average ages of 17, 24, and 29). At each time point, the variance in MPQ Constraint was due mostly to genetic (49\%-53\%) and nonshared environmental (42\%-50\%) influences. When the growth model factors were decomposed, they found significant genetic influences on both stability (68\%) and change (50\%), with no significant influence of the shared family environment. Genetic influences on stability are in many ways not surprising, but genetic influences on change, although they may seem paradoxical, are also critical to understand. Genetic influences on change may reflect the fact that genes operating on conscientiousness are expressed or diminished at different developmental stages, possibly as a result of "triggering" environments (a topic we turn to again when we discuss Gene $\times$ Environment Interplay, below). At least for earlier developmental stages, genetic influences tend to have a fairly important role in the stability and change of conscientiousness; it remains to be seen whether the environment may have a more important role in change at later ages or whether certain aspects of the construct (e.g., dutifulness, competence) may be more affected by the environment.

\section{Molecular Genetics of Conscientiousness}

Biometric modeling of twin and adoption data has convincingly demonstrated the importance of genetic influences on conscientiousness. Biometrical studies do not, however, tell us which genes explain the variation in a phenotype of interest. For this, molecular genetic methods are needed to uncover the segments of DNA that are associated with the phenotype. Even though molecular genetic approaches hold tremendous promise for unraveling the distal etiology of conscientiousness, it is important to remember that molecular personality genetics is in its infancy as a field. Along these lines, given that there is a substantial heritability component to most major personality traits, including conscientiousness, some may have assumed that finding the specific polymorphisms associated with these traits would be straightforward, and primarily a matter of applying contemporary technologies to personality phenotypes. However, the reliable identification of specific polymorphisms associated with personality has turned out to be a daunting endeavor. Importantly, this is not very different from the situation with other complex phenotypes, where the reliable identification of causal polymorphisms has also proved challenging (Visscher, Brown, McCarthy, \& Yang, 2012).

\section{Candidate Gene Research}

One approach to linking genetic polymorphisms with personality is to begin with polymorphisms in genes of known relevance to specific biological systems. Ideally, these polymorphisms would also be functional, that is, they would be known to change downstream products in persons with different alleles (different forms of genetic material at a specific genomic location). A number of these types of studies have been reported for conscientiousness; here, we offer a few illustrative examples.

Zuo et al. (2010) reported a study associating the alcohol dehydrogenase type 1A (ADH1A) gene with personality, the rationale being that ADH1A may be associated with substance dependence, and substance dependence is clearly associated with personality variation. They found that polymorphisms in ADH1A were associated with conscientiousness (as well as agreeableness), replicating this finding across three of the four samples they examined. M2 cholinergic receptor gene (CHRM2) is another candidate gene for substance dependence, and Luo et al. (2007) examined its potential relevance to personality (given evidence that personality traits and substance dependence share genetic variance in twin studies; Krueger et al., 2002), reporting associations with both conscientiousness and agreeableness.

Other heavily studied candidate polymorphisms may also be associated with conscientiousness. The well-known 5-HTTLPR (serotonin-transporter-linked polymorphic region) has typically been considered a candidate polymorphism for neuroticism and anxiety-related personality characteristics, but Harro et al. (2009) presented evidence that this polymorphism may also be associated with other traits, including conscientiousness, albeit they found this effect only in children as opposed to young adults. Similarly, monoamine oxidase A (MAOA) polymorphisms (particularly the well-known promoter region variable number tandem repeat) are typically considered candidates for aggressive traits, but Rosenberg et al. (2006) reported associations between other polymorphisms in MAOA, that is, haplotypes (combinations of single nucleotide polymorphisms, or "SNPs," that tend to be transmitted together), and conscientiousness.

\section{Genomewide Association Studies (GWAS)}

A more recent approach for associating genomic variation with phenotypes is known as a GWAS. GWAS involves genotyping of SNPs across the genome. Nucleotides are the basic building blocks of DNA. The human genotype consists of approximately 3 billion nucleotide bases, with the vast majority of these being "effectively monomorphic"; that is, the vast majority of people do not differ in which nucleotide they have at a specific position along the genome. Nevertheless, every thousand or so bases, there is a location where some people have one base but others have a different base, with a relatively higher frequency (e.g., the less common base or minor allele is present in $>1 \%$ of the population). These locations, where different people have different bases, are known as $S N P$ s. Present genotyping technology allows the characterization of millions of these SNPs across the genome, and those SNPs not genotyped on a particular platform can often be imputed by knowing the identity of nearby SNPs.

In a GWAS, SNPs across the genome are correlated (associated) with phenotypic variation, with no a priori hypotheses regarding where in the genome to seek variants that may predict the phenotype of interest. This strength of contemporary genotyping technology is also its Achilles' heel. Present genotyping platforms provide an overwhelming number of variables for association analysis. For example, if there are 1,000,000 SNPs genotyped in a GWAS, then there are 1,000,000 statistical tests performed, and a typical standard for declaring an effect "genome-wide significant" is to use the Bonferroni correction for the number of tests performed, such that the significance level adopted is $5 \times 10-8$ $(.05 / 1,000,000)$. As a result, the ability to detect signals among the extensive noise generated in this approach is limited at best. 
Recently, there was a major meta-analytic effort to assemble data from numerous studies, from around the globe, in which participants completed the NEO Five-Factor Inventory (Costa \& McCrae, 1992) and were also genotyped on a platform that provided SNP data across the genome. De Moor et al. (2012) report on the results of this effort. An overall sample of 17,375 adults provided both phenotypic and genotypic data for a discovery sample, and significant findings in the discovery sample were followed up in five replication samples $(N=3,294)$. Interestingly, an SNP (rs2576037) in the gene KATNAL2 (a gene expressed widely in the brain) reached a stringent threshold of genomewide significance in the discovery sample for conscientiousness, and the direction of effect for rs 2576037 was consistent in all the replication samples, albeit not statistically significant.

\section{Toward the Identification of Personality-Relevant Polymorphisms}

How can we best summarize the candidate gene and GWAS literatures on conscientiousness and what they indicate about the present state of the field? Although we reviewed a number of specific reports of candidate polymorphisms associated with conscientiousness, these reports are difficult to summarize easily. Essentially, a number of different plausible candidate polymorphisms may be associated with conscientiousness, and any gene known to be expressed in the brain is a plausible candidate, given our primitive understanding of the link between genomic and neural variation. Moreover, any specific report of an association between a candidate gene and personality must be replicated before we would have real confidence in the reliability of the association. Along these lines, candidate gene studies of other personality domains (approach- and avoidance-related traits, roughly extraversion and neuroticism) have been meta-analyzed, and these meta-analyses suggest that heavily researched candidate gene-personality associations are not replicable (Munafò, Brown, \& Hariri, 2008; Munafò et al., 2009). Although the GWAS findings of de Moor et al. (2012) for conscientiousness are intriguing, the potential relevance of KATNAL2 (which encodes a protein akin to the A subunit of the $\mathrm{p} 60$ katanin protein, a protein that may be relevant to neurodevelopment via its role in activities such as dendritic pruning) for conscientiousness obviously needs to be explored in other samples.

Where does this leave the field of molecular personality genetics? Recently, Munafò and Flint (2011) provided a thorough and sobering account of the state of research in this area. They argued that the data to date point to (a) no specific polymorphisms associated with personality being replicable so far and (b) the high likelihood that the polymorphisms relevant to personality variation are very large in number, with each polymorphism having an extremely tiny effect, taken individually. Consistent with this perspective, much recent GWAS-related research focuses on identifying large numbers of SNPs that, in tandem, predict phenotypic variation. For example, Middeldorp et al. (2011) constructed genomic risk scores derived from GWAS of personality traits and used these scores to predict major depression disorder (MDD) and bipolar disorder (BD) in separate samples. In this approach, numerous SNPs (thousands) are added to predict phenotypic variation, and then the resulting empirically keyed SNP scales are "cross-validated" in another sample (in this case, samples of per- sons with MDD and BD and control participants). Genomic risk scores keyed to neuroticism and extraversion were significant predictors of MDD and $\mathrm{BD}$, respectively, albeit the effect sizes were small $(0.1 \%$ of the variance in MDD and BD predicted). A reasonable conclusion from this work is that polygenic risk scores show promise in producing statistically significant, cross-validated findings; such scores may even ultimately provide "molecular indices" of personality trait variation (McCrae, Scally, Terracciano, Abecasis, \& Costa, 2010), albeit much more work needs to be done to unequivocally identify the thousands of polymorphisms presumably relevant to specific traits. Moreover, these scores contain thousands of SNPs in numerous genes and therefore tell us little about the biological pathways involved in personality and psychopathology.

In sum, understanding the molecular bases of personality variation remains a high priority, given the unequivocal relevance of personality to diverse outcomes and the clear evidence that genetic factors are important contributors to personality. Unfortunately, gene hunting for personality is likely to be extremely challenging work, and it may be a long while before we can definitively identify specific molecular genetic underpinnings of conscientiousness and other personality traits. Nevertheless, the ultimate payoff for this work could be tremendous in providing leads on the biological systems underlying human individual differences, and thereby the biological systems linked to outcomes such as healthy aging.

\section{New Strategies for Probing Conscientiousness and Healthy Aging}

As we demonstrated in the previous section, there is now abundant research documenting the magnitude of genetic and environmental influences on conscientiousness. There is also evidence of nontrivial genetic effects on several different aspects of healthy aging, including chronic illness, health behaviors, and global selfratings of health (e.g., Johnson \& Krueger, 2005; Li, Cheng, Ma, \& Swan, 2003; Svedberg, Lichtenstein, \& Pedersen, 2001). To date, these fields have proceeded mostly in parallel. The large phenotypic overlap between conscientiousness and health, however, suggests that inquiry at the intersection of these areas is likely to be very fruitful (Roberts \& Bogg, 2004; Roberts, Kuncel, Shiner, Caspi, \& Goldberg, 2007). It is somewhat surprising how little behavior genetic research has been done looking at the interplay between conscientiousness and health outcomes. Standard biometric modeling could be applied to conscientiousness and different health variables in order to determine the amount of genetic and environmental influences shared between these phenotypes. It may be fruitful, however, for research in this area to move beyond those models and instead use methods that can identify causal etiology. In this section, we discuss two relatively underused behavior genetic methods that could easily be applied to the study of conscientiousness and healthy aging.

\section{Cotwin Control}

The cotwin control method is a relatively straightforward strategy for examining the mechanisms underlying a phenotypic association. Instead of using twin data to decompose the variance of one or more phenotypes into genetic and environmental influences, 
the cotwin method uses the differences between twins to make causal inferences about the association between a hypothesized predictor and an outcome. The cotwin method essentially approximates the idealized counterfactual-a situation in which a researcher would determine the effect of an environmental risk factor by exposing and not exposing an individual to the risk and compare the outcomes in both cases. Clearly, the idealized counterfactual is not possible; treatment outcome studies attempt to come close by randomly assigning participants to different conditions and comparing groups. Unfortunately, a true experimental design would not be feasible for understanding most aspects of conscientiousness and healthy aging, as people cannot be assigned, for instance, to "conscientious" and "nonconscientious" conditions. Twins are, in a sense, a natural experiment, and can be used to approximate the idealized counterfactual model.

In this method, twins who are discordant on a predictor variable (e.g., personality trait, demographic variable, environmental risk factor, etc.) are compared on an outcome variable as a way of controlling for unobserved third variables (e.g., genetic, shared family environment) that may explain why the effect of the predictor on the outcome exists. For instance, a sample of twin pairs who are discordant on a variable of interest (i.e., one twin is currently married and one twin is not) can be assessed for the level of a second outcome variable (e.g., a health outcome). In the simplest version, the twin pairs would be MZ twins reared together, who share $100 \%$ of their genes and had the same family environment, and thus only differ to the extent that they have had different environmental experiences. Examining the likelihood of an outcome variable, $\mathrm{Y}$, in MZ twins who were discordant for the predictor $\mathrm{X}$ would be a powerful test of an environmentally mediated causal effect of $\mathrm{X}$ on $\mathrm{Y}$, given that this design controls for genetic and shared family effects. More complicated versions of the cotwin method compare the magnitude of association between $\mathrm{X}$ and $\mathrm{Y}$ within discordant $\mathrm{MZ}$ twins, within discordant $\mathrm{DZ}$ twins, and in unrelated individuals in the population (see, e.g., Burt et al., 2010). Essentially, the cotwin method is a way of getting closer to examining direct causal paths between variables by statistically controlling for both genetic and family environment factors. The predictor variable need not be a dichotomy, of course, but it is often conceptually easier to explain a twin's status as "exposed" and "not exposed," and we use the term discordant for simplicity's sake, understanding that this can typically be understood as "degree of discordance."

The cotwin control method has been used to examine several forms of psychopathology. For instance, studies have used this method to look at the mechanisms for overlapping vulnerability to childhood maltreatment and adult psychiatric disorders (Kendler et al., 2000; Young-Wolff, Enoch, \& Prescott, 2011). The application of this method to health outcomes is rarer. In a notable exception, Fujiwara and Kawachi (2009) used the twin sample from the Midlife in the United States (MIDUS) study to examine the causal effect of educational achievement on various health behaviors and conditions, including smoking, body mass index, physical activity, and global self-rated health. As the authors noted, education has long been associated with several health outcomes, but it is unclear whether this relationship is a result of unknown third variables (e.g., family and genetic factors). They used a fixed-effect twin method to control for these unmeasured variables and test a causal effect of education on health. In accord with previous findings, there were individual-level associations between years of schooling and health outcomes, including global physical and mental health, current smoking, and physical activity. By and large, however, the magnitude of associations within the MZ and DZ twins were much smaller, leading the authors to conclude that genetic and family factors explain much of the link between education and health; when these are controlled for, the association was greatly diminished.

To our knowledge, this method has never been applied to examine aspects of healthy aging and conscientiousness, even though it has great potential. Consider a hypothetical scenario in which this could be used, as portrayed in Figure 2. Again, the cotwin control method takes advantage of the fact that MZ and DZ twins who are reared together in the same household have not only known degrees of genetic relatedness but also share the same family environment. The first step is to identify an association between the predictor $X$ (here, conscientiousness) and a health outcome $\mathrm{Y}$ in the population. Next, we compare that individuallevel association with the magnitude of association between conscientiousness and health within discordant DZ twins, who share $50 \%$ of their genes and all family environment, and within discordant MZ twins, who share $100 \%$ of their genes and all family environment. In Scenario A, there was an association between conscientiousness and the health outcome at the individual level, within $\mathrm{MZ}$ twins discordant on conscientiousness, and within DZ twin pairs discordant on conscientiousness. This would be the strongest evidence that conscientiousness is a direct environmental causal agent on health. It is also possible that there would be an association between conscientiousness and health at the individual level, but it would be reduced or nonsignificant within the discordant MZ twin pairs and within the discordant DZ twin pairs (see Scenario B). This would suggest that the association between

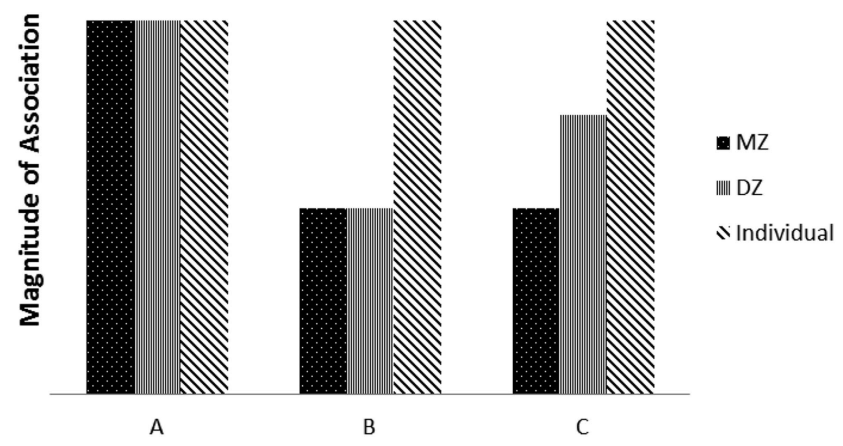

Figure 2. Interpretation of three possible cotwin control result patterns. If the association between conscientiousness and a health outcome were the same at the individual level, among MZ twins discordant on conscientiousness, and among DZ twins discordant on conscientiousness, it would suggest an environmentally mediated causal link between predictor and outcome (Scenario A). If the association were observed at the same level within discordant $\mathrm{MZ}$ twin pairs and within discordant DZ twins but at a greater magnitude at the individual level, it would indicate that family factors (both genetic and environmental) may account for the association between predictor and outcome (Scenario B). If the association was greater at the individual level, weaker within discordant DZ twins, and weaker still within discordant MZ twins, it would suggest that unmeasured genetic factors may account for the association between predictor and outcome (Scenario C). MZ = monozygotic; $\mathrm{DZ}=$ dizygotic. 
conscientiousness and health is noncausal, but instead due to shared family effects (both genetic and environmental) that lead to both low conscientiousness and health problems. Finally, it is possible that the association between personality and health is due solely to overlapping genetic influences (see Scenario C). In that case, there would be a significant association between conscientiousness and health at the individual level, but the association would be lower in magnitude within discordant DZ twins, and would be even smaller still within discordant MZ twins.

The cotwin method thus provides researchers with an analytic strategy that is relatively easy to implement and conceptually simple to interpret. Given the strengths of this method, it is surprising that it is not more widely applied in the study of healthy aging (for a recent review, see McGue, Osler, \& Christensen, 2010; see also Eaton et al., 2012). One notable exception looked at the relationship between a personality factor (well-being) and late-life mortality; applying the cotwin control method, McGue et al. found that the relationship was independent of family factors, supporting a causal mechanism between subjective well-being and longevity (Sadler, Miller, Christensen, \& McGue, 2011). Conscientiousness might serve as an important unifying theme to organize this research, given the links between the trait and so many different aspects related to positive aging. We could see this method easily being implemented to examine the causal effect of conscientiousness on health behaviors (e.g., physical activity), health conditions (e.g., chronic illness), and other aspects of healthy aging (e.g., perception of financial security).

Of course, it is important to note that the cotwin control method does not rule out the possibility of either a third variable that influences both X (i.e., conscientiousness) and Y (i.e., health) and that would technically fall under the "nonshared" environment. Detrimental peer groups, or "drinking buddies," may be one example of an influence that leads to lower levels of conscientiousness and worse health. Another problem is the possibility of reverse causation; although it is intuitively appealing to think about preexisting trait levels of conscientiousness influencing later health, it is entirely possible that health problems would impact someone's level of conscientiousness. Both of these problems may best be addressed with longitudinal designs, a topic we return to again below.

\section{Gene-Environment Interplay}

As noted above, classic behavior genetic modeling with twin studies fit the data on one or more phenotypes to structural equation models that can estimate genetic and environmental components for each variable; in the case of multivariate models, we can also calculate estimates of things like bivariate heritability and genetic and environmental correlations (e.g., the amount of overlap between genetic influences on one variable and genetic influences on the other variable). There are two important caveats that we need to make about these estimates. First, it is important to remember that heritability (and the commensurate estimates for shared and nonshared environment) are proportions of variance and explain how much of the variance in a phenotype (like physical health) can be explained by the relative influences of genes and environment. Heritability does not tell us anything about the genetic effects on any one individual's health. Second, and related, it should also be noted that these models result in sample-specific population estimates. That is, they are population parameters in the same way that mean and variance estimates of a variable are averaging over any differences within that population on other variables. Keeping these two points in mind, we can qualify the statement "the heritability of personality is roughly 50\%" thusly: Within a twin sample that is drawn from a certain population, there is variation in personality traits for that sample, and, averaging across any differences between people within this sample, $50 \%$ of that variation can be explained by genetic differences between individuals

Researchers who use behavior genetic methods have always acknowledged this limitation, and studies in which gender, age, and cultural differences in heritability estimates are examined are an attempt to get at whether there are real differences in these variance components between certain segments of the population. Only recently have models been developed that allow for more complex and formal testing of whether the ACE components of variance may differ as a function of important environmental contexts (Purcell, 2002). These biometric moderation models are a way of looking at two important forms of gene-environment interplay: gene-environment correlation $(\mathrm{rGE})$ and Gene $\times$ Environment interaction $(\mathrm{G} \times \mathrm{E})$. Formally, $r G E$ refers to the idea that genetically based tendencies will lead people to seek out certain types of environments (e.g., an introverted person will be more likely to look for a career that does not require a lot of interaction with people) or evoke certain reactions from other people (e.g., a neurotic individual will elicit negative reactions from others). The statistical test for rGE is the genetic correlation between two variables in a multivariate biometric model, which indexes the amount of overlap in the genetic influences on two phenotypes and ranges from -1 to +1 ; correlations for shared and nonshared environment are also estimated. Biometric moderation models can estimate these genetic and environmental correlations at differing levels of the moderator variable.

In addition to $\mathrm{rGE}, \mathrm{G} \times \mathrm{E}$ is also possible. $\mathrm{G} \times \mathrm{E}$ is obtained when genetic influences on a phenotype-like physical health are only expressed or triggered in the presence of a specific environmental factor (like personality). Models that test for $\mathrm{G} \times \mathrm{E}$ result in different estimates of heritability at different levels of a second moderator variable (similar to the ways in which different heritability estimates can be obtained for men and women when examining sex differences in ACE estimates). In effect, this model gets closer to bringing heritability to an individual-specific level. In previous research, for instance, we have shown that if a person has a high level of marital quality, the heritability of internalizing psychopathology is low, compared with higher heritability for a person with low levels of marital quality (South \& Krueger, 2008).

These models are now used more frequently in the literature but are still relatively underused when one considers the potential moderators and potential outcomes that could be modeled. Most frequently, these models have been used to examine geneenvironment interplay for externalizing (Burt, McGue, Demarte, Krueger, \& Iacono, 2006; Dick et al., 2007; Hicks, South, DiRago, Iacono, \& McGue, 2009) and internalizing psychopathology (South \& Krueger, 2008, 2011). In an example involving personality traits, Krueger and colleagues used data from the Minnesota Twin Family Study to examine whether the parent-adolescent relationship moderates the genetic and environmental influences on the adolescent's self-reported personality (Krueger et al., 2008). 
The amount of parental regard and parent-child conflict moderated genetic effects on adolescent's MPQ Positive Emotionality (PEM) and Negative Emotionality (NEM). For instance, genetic effects on PEM were much greater at higher levels of parental regard than at lower levels of parental regard. What is notable about these findings is that $\mathrm{G} \times \mathrm{Es}$ were also found when the direction of effect was reversed and adolescent personality acted as the moderator of the parent-adolescent relationship (South, Krueger, Johnson, \& Iacono, 2008). Of particular interest for the present discussion, MPQ Constraint significantly moderated parental regard: At low levels of Constraint, the proportion of variance in parental regard was $30 \% \mathrm{~A}, 37 \% \mathrm{C}$, and $32 \% \mathrm{E}$, whereas at high levels of Constraint, variances estimated were $65 \%$ A, $15 \%$ $\mathrm{C}$, and $20 \% \mathrm{E}$.

Personality as a moderator of genetic and environmental influences on a phenotype is a relatively novel way to think about the impact of personality on developmental outcomes, and has implications for future work in the area of Conscientiousness and health. If we think of Conscientiousness as a relatively stable, enduring personality trait that has substantial genetic influences (which in fact contribute largely to its stability), then we can start to understand how a person's level of this trait may lead them to encounter certain situations (an example of rGE), which could in turn have an impact on genetic influences on aspects of healthy aging $(\mathrm{G} \times \mathrm{E})$. We turn next to an empirical example of what is possible in this area using these biometric moderation models.

\section{An Empirical Example: Conscientiousness as a Moderator of Problem Alcohol Use}

For an empirical example of gene-environment interplay between conscientiousness and an aspect of healthy aging, we turned to a health behavior that has far-reaching consequences for successful aging - alcohol use problems. Problem alcohol use is heritable (Agrawal \& Lynskey, 2008), widely prevalent (Hasin, Stinson, Ogburn, \& Grant, 2007), and one of the most preventable causes of mortality and morbidity (World Health Organization, 2002). It can result in actions that have both more (e.g., cirrhosis of the liver) and less direct (e.g., marital conflict) effects on health outcomes. Low levels of conscientiousness (or high levels of disinhibition) are strongly associated with alcohol use on a phenotypic level (Roberts \& Bogg, 2004); structural models of psychopathology often include disinhibition and alcohol use disorders within a higher order dimension of externalizing psychopathology (e.g., Krueger, Markon, Patrick, Benning, \& Kramer, 2007). Here, we explore one possible mechanism of this association: the idea that high levels of conscientiousness moderate the genetic and environmental influences on problem alcohol use.

\section{Method}

Participants. Data came from the twin sample of the MacArthur Foundation Survey of MIDUS study (Kessler, Gilman, Thornton, \& Kendler, 2004; Kendler, Thornton, Gilman, $\&$ Kessler, 2000). The MIDUS twin sample is unique in being nationally representative, with a wide age range of adult participants who responded to numerous questions related to physical health, individual differences, and social support, among other measures. The MIDUS twin sample was ascertained through the use of a telephone survey, which screened members of approximately 50,000 households to determine whether an immediate relative was a twin (Kessler et al., 2004). A total of $14.8 \%$ of the respondents identified a twin relative, and $60 \%$ agreed to be contacted for study recruitment. The final response rate for complete twin interviews (i.e., an interviewer contacted both members of the twin pair, both twins agreed to participate, and both twins completed a short zygosity screening questionnaire) was approximately $26 \%$. All twin participants completed the full MIDUS data collection, which consisted of two mailed questionnaire booklets and a computer-assisted telephone interview (Kessler et al., 2000), between 1994 and 1995.

A total of 1,996 individuals from 998 twin pairs were enrolled in the MIDUS twin sample. A twin screener was used to determine zygosity by asking participants about physical similarity (e.g., eye and hair color) and degree to which others were confused about their identity during childhood. These and similar techniques are usually accurate more than $90 \%$ of the time (Lykken, Bouchard, McGue, \& Tellegen, 1990). We excluded pairs with missing or indeterminate zygosity information and opposite-sex pairs; the moderation model also eliminates twin pairs if both members of the pair do not have data on the moderator. The final sample consisted of 590 twin pairs: $141 \mathrm{MZ}$ male pairs, $173 \mathrm{MZ}$ female pairs, $108 \mathrm{DZ}$ male pairs, and $168 \mathrm{DZ}$ female pairs. Average age was $44.6(S D=12.16$, range $=25-74)$. All participants provided informed consent, and the present study was approved by the authors' local Institutional Review Boards.

Measures. For these analyses, we used measures of conscientiousness and alcohol use problems. The Conscientiousness scale is based on the Big Five Model (BFM) of personality (Lachman \& Weaver, 1997). Each of the BFM domains was assessed with trait adjectives chosen from existing trait measures. Conscientiousness consists of the following four adjectives, each rated on a 4-point scale $(1=$ a lot $; 2=$ some $; 3=$ a little $; 4=$ not at all): organized, responsible, hardworking, careless (reverse coded). As reported previously (Johnson \& Krueger, 2004), the internal consistency of this scale was modest $(\alpha=.58)$. For alcohol problems, we used seven items included in the MIDUS questionnaires. Five items are dichotomous (yes/no) items that ask whether alcohol use resulted in the following during the past 12 months: under the effects or aftereffects of alcohol in a situation which increased chances of getting hurt (e.g., driving a car); any emotional or psychological problems from using alcohol; strong desire or urge to use alcohol that one could not resist; a month or more of spending a great deal of time spent using alcohol or getting over its effects; needed to use more alcohol than usual to get the same effect. Two additional items asked for a rating of frequency of (a) using much larger amounts of alcohol than intended or for a longer period of time than intended and (b) being under the effects or aftereffects of alcohol while at work or school, or while taking care of children. These two additional items were rated on a 6-point scale $(1=$ never, $2=$ once or twice, $3=3$ to 5 times, $4=6$ to 10 times, $5=11$ to 20 times, $6=$ more than 20 times), but for the purposes of these analyses we dichotomized them such that $0=$ never and $1=$ ever happened, to make them commensurate with the other five dichotomous items. A total alcohol problems score was created by summing the resulting seven dichotomous items (if data were present on at least five of the seven items). 
Average score on conscientiousness was $3.44(S D=0.44$, range $=1.75-4.00$, skew $=-0.80)$. The mean number of items endorsed for alcohol problems was $0.50(S D=1.08$, range $=0-7$, skew $=2.80$ ). We transformed both the conscientiousness (squareroot transformation, which was reflected to result in higher scores equaling greater conscientiousness, resulting variable skew = -.48) and alcohol problems (inverse transformation, resulting variable skew $=-1.33$ ) variables to separate level from variance as would be expected in a normal regression model.

Data analysis. For these analyses, we used a biometric moderation model first articulated by Purcell (2002). The moderation model (see Figure 3) is essentially an extension of a bivariate (Cholesky) decomposition, which estimates genetic and environmental influences shared in common between two variables. Just as in a no-moderation bivaraiate model, we include latent variables that correspond to additive genetic, shared (common) environmental, and nonshared environmental variance in Conscientiousness as well as the variance that is shared between Conscientiousness and Alcohol Problems $\left(\mathrm{A}_{\mathrm{c}}, \mathrm{C}_{\mathrm{c}}\right.$, and $\left.\mathrm{E}_{\mathrm{c}}\right)$. Variables $\mathrm{A}_{\mathrm{u}}, \mathrm{C}_{\mathrm{u}}$, and $\mathrm{E}_{\mathrm{u}}$ stand for any residual variance in Alcohol Problems after accounting for Conscientiousness. Where the moderation model differs from the no-moderation model is in the ability to incorporate level of the moderator in determining genetic and environmental variance. Each of the paths influencing Alcohol Problems is a linear function that combines (a) an overall coefficient (e.g., $a_{c}$ ), separate from the moderator variable, that indicates the magnitude of each effect of $\mathrm{A}, \mathrm{C}$, or $\mathrm{E}$ on Alcohol, and (b) the product of a coefficient that indexes the moderation of Alcohol by Conscientiousness $\left(\beta_{X_{c}}\right)$ multiplied by the level of the moderator $(\mathrm{M})$. The resulting parameter estimates can be used to plot the model-predicted genetic and environmental components of variation for Alcohol Problems across different levels of Conscientiousness; the standardized pro- portions of variance (e.g., the heritability quotient) can be plotted as well.

As a first step, the full biometric moderation model was fit to the raw data for conscientiousness and alcohol problems. Next, the six moderation parameters were dropped and a no-moderation model was fit to the data, and the fit of the two models was compared. All models were fit to raw data in Mx (Neale, Boker, Xie, \& Maes, 2003a) using full information maximum likelihood, a method that handles missing data in the outcome variable as part of the model fitting procedure. To correct for potential biases of gender and age on model fitting, the transformed conscientiousness and alcohol problems scores were regressed on age, age $^{2}$, Age $\times$ Gender, and $\mathrm{Age}^{2} \times$ Gender (McGue \& Bouchard, 1984), and the residuals used in modeling. Fit of the model was evaluated using the likelihood ratio test (LRT) and the Akaike information criterion (AIC; Akaike, 1987). The LRT corresponds with the difference in the $-2 \log$-likelihood values for two separate models and is distributed as chi-square. When there is a statistically significant change in LRT between two different models, this can indicate improvement in the model's fit as a result of adding or omitting parameters. An information-theoretic fit statistic, AIC balances fit and number of parameters when choosing the best fitting model, with lower AIC values indicating better fitting models (Markon \& Krueger, 2004).

\section{Results and Discussion}

The raw conscientiousness score was significantly correlated with the total alcohol problems score $(r=-.08, p<.01)$. The alcohol problems score was reversed (to ensure a positive covariance in the biometric model) and transformed prior to age and gender correction; the correlation between the standardized scores

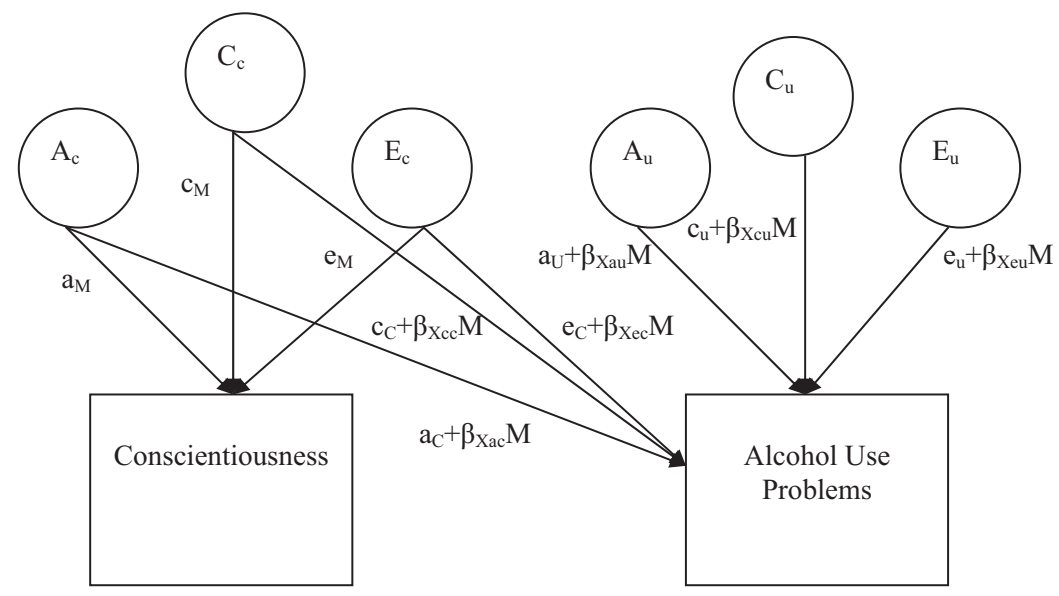

Figure 3. Full biometrical moderation model with Conscientiousness moderating the genetic and environmental influences on Alcohol Use Problems (model is shown for only one member of the twin pair). A signifies influences due to additive genetics, $\mathrm{C}$ refers to shared (common) environmental influences, and $\mathrm{E}$ refers to nonshared (unique) environmental variance. $\mathrm{A}_{\mathrm{c}}, \mathrm{C}_{\mathrm{c}}$, and $\mathrm{E}_{\mathrm{c}}$ represent the common variance shared between Conscientiousness and Alcohol, whereas $\mathrm{A}_{\mathrm{u}}, \mathrm{C}_{\mathrm{u}}$, and $\mathrm{E}_{\mathrm{u}}$ represent any residual variance in Alcohol after accounting for Conscientiousness. Moderation of Alcohol by Conscientiousness is represented by the product of a coefficient that indexes the direction and magnitude of moderation (e.g., $\beta_{\mathrm{Xc}}$ ) multiplied by the level of the moderator. The total phenotypic variance in Alcohol can be calculated by squaring and summing all of the paths leading to it: $\mathrm{P}^{2}=\left(\mathrm{a}_{\mathrm{C}}+\beta_{\mathrm{Xac}} \mathrm{M}\right)^{2}+\left(\mathrm{a}_{\mathrm{U}}+\beta_{\mathrm{Xau}} \mathrm{M}\right)^{2}+\left(\mathrm{c}_{\mathrm{C}}+\beta_{\mathrm{Xcc}} \mathrm{M}\right)^{2}+\left(\mathrm{c}_{\mathrm{U}}+\beta_{\mathrm{Xcu}} \mathrm{M}\right)^{2}+\left(\mathrm{e}_{\mathrm{C}}+\beta_{\mathrm{Xec}} \mathrm{M}\right){ }^{2}+$ $\left(\mathrm{e}_{\mathrm{U}}+\beta_{\mathrm{Xeu}} \mathrm{M}\right)^{2}$. 
for conscientiousness and alcohol problems was .07 $(p<.05)$. First, we entered the $z$ scores for the transformed conscientiousness and alcohol problems variables into the full moderation model $(-2$ $\log$ likelihood $=6456.64, d f=2328$, AIC $=1800.64)$. Next, we ran a no-moderation model in which the six moderation parameters were dropped. This model is equivalent to the bivariate decomposition (Cholesky) model, except that the design of the statistical model is such that the raw data file that is read by the Mx script includes repeat columns for the moderator variable for each twin (i.e., the moderator is entered twice; see Purcell, 2002). This results in different $-2 \log$ likelihood and degrees of freedom than would be obtained from a Cholesky. The no-moderation model $(-2 \log$ likelihood $=6469.77, d f=2334$, AIC $=1801.77)$ fit significantly worse than the moderation model according to the LRT $(\Delta-2 \operatorname{lnL}=13.13, \Delta d f=6, p<.05)$, so it is possible to conclude that a model specifically allowing for $\mathrm{G} \times \mathrm{E}$ fits better than a model that does not include $\mathrm{G} \times \mathrm{E}$.

Panel A of Figure 4 demonstrates the change in the raw genetic and environmental components of variance of alcohol problems as a function of level of conscientiousness (see also Table 1). Variance components can be plotted for any level of the moderator (i.e., for a specific raw value of the moderator, ACE estimates can be calculated for the variable that is being moderated), but for simplicity's sake, we plot them here at seven different levels of conscientiousness $(-3,-2,-1,0,1,2$, and $3 S D$ s away from the mean). The genetic variance in alcohol problems showed a slight curvilinear pattern, with the lowest value at the mean of conscientiousness and slightly higher estimates at the extremes. ${ }^{1}$ The nonshared environmental variance decreased from low to high levels of conscientiousness, whereas the shared environmental variance was essentially negligible at any level of conscientiousness. As a result of the fact that the raw $E$ variance decreased substantially while the raw A variance displayed much less change across the level of conscientiousness, the heritability (i.e., proportion of variance) of alcohol problems increased from low to high levels of conscientiousness (see Panel B, Figure 4, and Table 1). Similarly, the genetic correlations between conscientiousness and alcohol problems increased from low $\left(r_{\mathrm{a}}=-.23\right)$ to high $\left(r_{\mathrm{a}}=\right.$ .47) levels of conscientiousness (see Table 1). Overlap between the nonshared environmental influences on conscientiousness and alcohol problems was relatively low at every level of conscientiousness.

We can conclude that etiological influences on alcohol use problems differ as a function of a person's level of conscientiousness. At low levels of conscientiousness (or, to put it another way, in a more disinhibited person), the nonshared environment has a greater influence on alcohol use problems. Conscientiousness appears to buffer against the sibling-specific effects of the nonshared environment on likelihood of alcohol use problems. One plausible interpretation is that this happens because a disinhibited person does not have the level of conscientiousness required to impose organization on the environment. When a person has relatively higher levels of conscientiousness, however, the nonshared environment matters less. As a result, alcohol problems in the context of higher levels of conscientiousness are, proportionately speaking, more of a function of genetic variation. The clarity of the genetic risk for alcohol problems is greater at higher levels of conscientiousness, whereas at lower levels of conscientiousness, events related to the nonshared environment (sibling-specific ef- fects, for instance, the romantic partner who one chooses) have a greater impact on alcohol problems. Put somewhat differently, alcohol problems in the context of higher conscientiousness may be related to heritable risk for alcohol problems, because at lower levels of conscientiousness, there is greater variance in alcohol problems, traced to a larger amount of random, nonshared environmental influences.

We can envision several applications of this type of modeling to the study of conscientiousness and health, as prompted by the other articles in this special section. Our results with regard to conscientiousness and alcohol are in line with the findings of Kern, Hampson, Goldberg, and Friedman (2014), who report that alcohol abuse mediated the relationship between childhood conscientiousness and adult health. The biometric moderation model could be applied to examine these relationships in a sample followed from childhood to adulthood to determine whether the $\mathrm{G} \times \mathrm{E}$ effect we found in adults extends to a life span developmental influence of childhood and adolescent conscientiousness on health behaviors later in life. Another possible application of the moderation model would be to examine social context and conscientiousness. As suggested by Shanahan, Hill, Roberts, Eccles, and Friedman (2014), SES is a context that may moderate the heritability of conscientiousness, in turn affecting the ability of individuals to cope with illness. One possible application would be to use the moderation model with variables like income and education as the moderator and conscientiousness as the downstream variable; in previous work, we have found that income moderates the heritability of internalizing psychopathology (anxiety and depression), with higher heritability found at the highest levels of income (South \& Krueger, 2011). A similar process may operate for conscientiousness, with higher SES allowing for the full expression of genetic influences on conscientiousness.

Finally, we advocate for the application of both the biometric moderation model used in the present analyses and the cotwin control method described above to longitudinal data. Here, we specifically mean data for which a health measure and a conscientiousness measure are collected at two or more points in time. Even a more basic longitudinal, multivariate (i.e., Cholesky decomposition) biometric model would be informative as a means of exploring whether premorbid trait conscientiousness is a manifestation of the same genetic influences that influence later health. Extending this model to include a potential mediator, for instance, education level or addiction potential (see Friedman, Kern, Hampson, \& Duckworth, 2014), would be a means of testing the extent to which genes common to personality, education, and health account for a portion of this mediation. Longitudinal designs as applied to the cotwin control method would be a way of controlling for the potential third-variable problem (discussed above), as this decreases the chances that a third variable would be present and operating across time points. Finally, applying the biometric moderation model to longitudinal data would be stronger evidence as to the causal mechanisms operating between conscientiousness and health, as it would be possible to test moderation of health at

\footnotetext{
${ }^{1}$ The moderation model fit to these data is linear in its individual components (see Figure 3), but the resulting ACE estimates can look nonlinear when model-predicted values are plotted at different levels of the moderator variable (see Purcell, 2002, for further details).
} 
A

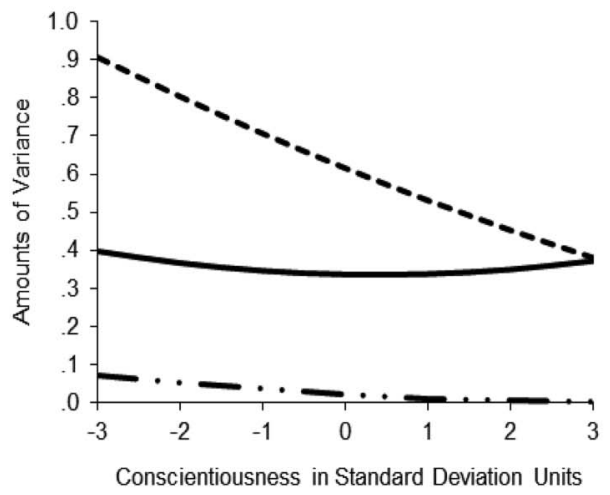

B

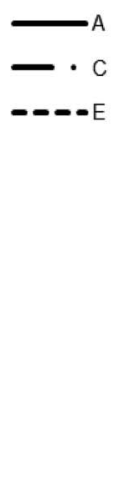

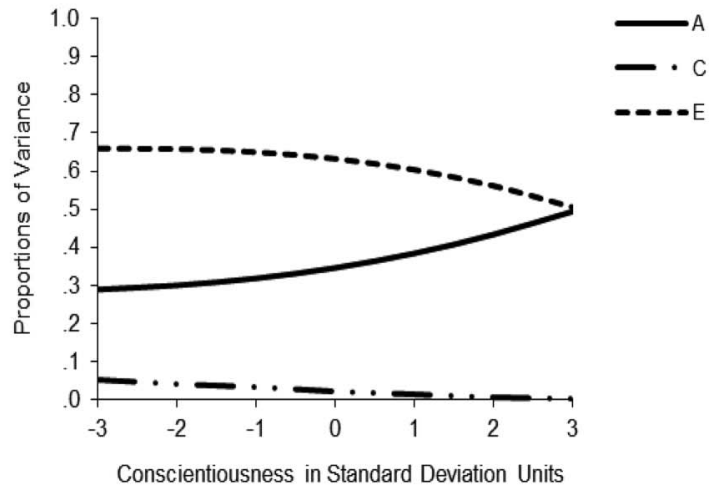

Figure 4. Panel A: Genetic and environmental amounts of variance in Alcohol Problems as a function of Conscientiousness. Panel B: Proportions of variance in Alcohol Problems as a function of Conscientiousness. $\mathrm{A}=$ genetic influences; $\mathrm{C}=$ shared environmental influences; $\mathrm{E}=$ nonshared environmental influences.

a later time point as a function of conscientiousness at an earlier time point. To our knowledge, none of these types of designs have been executed, leaving many potential avenues of research for the future.

\section{Summary and Future Directions}

Conscientiousness, like most other major domains of personality, has substantial genetic influences. This has been confirmed across gender, ages, and numerous samples, using varied measurement instruments with overlapping conceptualizations of the conscientiousness construct. It is probably safe to say that we no longer need behavior genetic methods simply to establish a (partly) genetic basis to the trait. Rather, as the study of conscientiousness moves forward, behavioral and molecular genetics methods can assist in shedding light on what conscientiousness is and how and why conscientiousness is manifested in a variety of outcomes.
First, behavior genetic methods can be used to further delineate the construct of conscientiousness. This will aid in the refinement of assessment instruments for conscientiousness, which will in turn strengthen our understanding of what aspects of conscientiousness are most important for understanding healthy aging. Better measurement of the conscientiousness construct also will aid in focusing targets for molecular genetics research, which to date has identified few specific molecular variants reliably associated with behavioral phenotypes (Collins, Ellickson, \& Klein, 2007) and is plagued by difficulties with replication (Munafò et al., 2003). Second, behavior genetic methods can continue to tease out the relative importance of genes and environment over time. Not only may genetic influences on health change as a function of an individual's age, it is possible that there are cohort differences on aspects of health and health behaviors. For instance, researchers recently used the MIDUS twin sample to demonstrate that genetic influences on smoking decreased dramatically following an in-

Table 1

Estimates of Unstandardized and Standardized Variance Components and Genetic and Environmental Correlations Between Conscientiousness and Alcohol Use Problems

\begin{tabular}{|c|c|c|c|c|c|c|c|c|c|c|c|}
\hline \multirow[b]{2}{*}{ Variable } & & \multicolumn{3}{|c|}{ Variance components } & \multirow{2}{*}{$\begin{array}{c}\text { Total } \\
\text { variance }\end{array}$} & \multicolumn{3}{|c|}{ Proportions of variance } & \multicolumn{3}{|c|}{ Correlations with moderator } \\
\hline & & A & $\mathrm{C}$ & $\mathrm{E}$ & & $\mathrm{A}(\%)$ & $\mathrm{C}(\%)$ & $\mathrm{E}(\%)$ & $\mathrm{rA}$ & $\mathrm{rC}$ & $\mathrm{rE}$ \\
\hline \multicolumn{12}{|l|}{ No-moderation model } \\
\hline Conscientiousness & & 0.43 & 0.00 & 0.55 & 0.98 & 0.44 & 0.00 & 0.56 & - & - & - \\
\hline Alcohol Use Problems & & 0.36 & 0.00 & 0.62 & 0.98 & 0.37 & 0.00 & 0.63 & 0.03 & -1.00 & 0.09 \\
\hline \multicolumn{12}{|c|}{ Moderation model } \\
\hline \multirow{7}{*}{$\begin{array}{l}\text { Alcohol Use Problems } \\
\text { of Conscientiousness }\end{array}$} & -3 & 0.40 & 0.07 & 0.91 & 1.37 & 0.29 & 0.05 & 0.66 & -0.23 & -1.00 & 0.09 \\
\hline & -2 & 0.37 & 0.05 & 0.80 & 1.22 & 0.30 & 0.04 & 0.66 & -0.12 & -1.00 & 0.09 \\
\hline & -1 & 0.35 & 0.03 & 0.71 & 1.09 & 0.32 & 0.03 & 0.65 & -0.01 & -1.00 & 0.09 \\
\hline & 0 & 0.34 & 0.02 & 0.62 & 0.97 & 0.35 & 0.02 & 0.63 & 0.12 & -1.00 & 0.09 \\
\hline & 1 & 0.34 & 0.01 & 0.53 & 0.88 & 0.38 & 0.01 & 0.60 & 0.24 & -1.00 & 0.10 \\
\hline & 2 & 0.35 & 0.00 & 0.45 & 0.81 & 0.43 & 0.01 & 0.56 & 0.36 & -1.00 & 0.10 \\
\hline & 3 & 0.37 & 0.00 & 0.38 & 0.75 & 0.49 & 0.00 & 0.51 & 0.47 & -1.00 & 0.10 \\
\hline
\end{tabular}

Note. $\mathrm{A}=$ unstandardized genetic variance component; $\mathrm{C}=$ unstandardized shared environmental variance component; $\mathrm{E}=$ unstandardized nonshared environmental variance component; $\mathrm{A}(\%)=$ standardized genetic variance proportion; $\mathrm{C}(\%)=$ standardized shared environmental variance proportion; $\mathrm{E}(\%)=$ standardized shared environmental variance proportion; $\mathrm{rA}=$ genetic correlation; $\mathrm{rC}=$ shared environmental correlation; $\mathrm{rE}=$ nonshared environmental correlation. Dashes indicate that no value is needed here because there is only one correlation between Conscientiousness and Alcohol Use Problems, and it appears in the line below. 
crease in legislation banning smoking in public places (Boardman, Blalock, \& Pampel, 2010). Third, and finally, we recommend an organized and systematic investigation of the interplay between conscientiousness and healthy aging through the use of underused methodologies. The cotwin control method is an ideal way of determining whether there are causal effects of conscientiousness on health outcomes. Biometric moderation models are able to identify Gene $\times$ Eenvironment interactions between conscientiousness and health, which has both the potential to immediately inform prevention and intervention research and the potential to lay the groundwork for future molecular genetics research.

\section{References}

Agrawal, A., \& Lynskey, M. T. (2008). Are there genetic influences on addiction: Evidence from family, adoption and twin studies. Addiction, 103, 1069-1081. doi:10.1111/j.1360-0443.2008.02213.x

Akaike, H. (1987). Factor analysis and AIC. Psychometrika, 52, 317-332. doi:10.1007/BF02294359

Bergeman, C. S., Chlpuer, H. M., Plomin, R., Pedersen, N. L., McClearn, G. E., Nesselroade, J. R., . . . McCrae, R. R. (1993). Genetic and environmental effects on Openness to Experience, Agreeableness, and Conscientiousness: An adoption/twin study. Journal of Personality, 61, 159-179. doi:10.1111/j.1467-6494.1993.tb01030.x

Bleidorn, W., Kandler, C., Riemann, R., Angleitner, A., \& Spinath, F. M. (2009). Patterns and sources of adult personality development: Grown curve analyses of the NEO-PI-R scales in a longitudinal twin study. Journal of Personality and Social Psychology, 97, 142-155. doi: 10.1037/a0015434

Blonigen, D. M., Carlson, M. D., Hicks, B. M., Krueger, R. F., \& Iacono, W. G. (2008). Stability and change in personality traits from late adolescence to early adulthood: A longitudinal twin study. Journal of Personality, 76, 229-266. doi:10.1111/j.1467-6494.2007.00485.x

Boardman, J. D., Blalock, C. L., \& Pampel, F. C. (2010). Trends in the genetic influence on smoking. Journal of Health \& Social Behavior, 51, 108-123. doi:10.1177/0022146509361195

Bouchard, T. J., Jr., \& Loehlin, J. C. (2001). Genes, evolution, and personality. Behavior Genetics, 31, 243-273. doi:10.1023/A: 1012294324713

Buchanan, J. P., McGue, M., Keyes, M., \& Iacono, W. (2009). Are there shared environmental influences on adolescent behavior? Evidence from a study of adopted siblings. Behavior Genetics, 39, 532-540. doi: 10.1007/s10519-009-9283-y

Burt, S. A., Donnellan, B. M., Humbad, M. N., Hicks, B. M., McGue, M., \& Iacono, W. G. (2010). Does marriage inhibit antisocial behavior? An examination of selection vs. causation via a longitudinal twin design. Archives of General Psychiatry, 67, 1309-1315. doi:10.1001/ archgenpsychiatry.2010.159

Burt, S. A., McGue, M., Demarte, J. A., Krueger, R. F., \& Iacono, W. G. (2006). Timing of menarche and the origins of conduct disorder. Archives of General Psychiatry, 63, 890-896. doi:10.1001/archpsyc.63.8 .890

Cloninger, C., Svrakic, D., \& Przybeck, T. (1993). A psychobiological model of temperament and character. Archives of General Psychiatry, 50, 975-990. doi:10.1001/archpsyc.1993.01820240059008

Collins, R. L., Ellickson, P. L., \& Klein, D. J. (2007). The role of substance use in young adult divorce. Addiction, 102, 786-794. doi:10.1111/j .1360-0443.2007.01803.x

Costa, P. T., \& McCrae, R. R. (1992). Revised NEO Personality Inventory (NEO-PI-R) and NEO Five-Factor Inventory (NEO-FFI) professional manual. Odessa, FL: Psychological Assessment Resources.

de Moor, M. H. M., Costa, P. T., Terracciano, A., Krueger, R. F., de Geus, E. J. C., Toshiko, T., . . . Boomsma, D. I. (2012). Meta-analysis of genome-wide association studies for personality. Molecular Psychiatry, 17, 337-349.

Dick, D. M., Viken, R., Purcell, S., Kaprio, J., Pulkkinen, L., \& Rose, R. J (2007). Parental monitoring moderates the importance of genetic and environmental influences on adolescent smoking. Journal of Abnormal Psychology, 116, 213-218. doi:10.1037/0021-843X.116.1.213

Eaton, N. R., Krueger, R. F., South, S. C., Gruenewald, T. L., Seeman, T., \& Roberts, B. W. (2012). Genes, environments, personality, and successful aging: Toward a comprehensive developmental model in later life. Journals of Gerontology, Series A: Biological Sciences and Medical Sciences, 67, 480-488.

Eisenberg, N., Duckworth, A. L., Spinrad, T. L., \& Valiente, C. (2014) Conscientiousness: Origins in childhood? Developmental Psychology, 50, 1331-1349. doi:10.1037/a0030977

Eysenck, H. J. (1991). Dimensions of personality: 16, 5, or 3? Criteria for a taxonomic paradigm. Personality and Individual Differences, 12, 773790. doi:10.1016/0191-8869(91)90144-Z

Eysenck, H. J., \& Eysenck, S. B. G. (1975). Manual of the Eysenck Personality Questionnaire. San Diego, CA: Educational and Industrial Testing Service.

Farone, S. V., Tsuang, M. T., \& Tsuang, D. W. (1999). Genetics of mental disorders. New York, NY: Guilford Press.

Finkel, D., \& McGue, M. (1997). Sex differences and nonadditivity in the heritability of the Multidimensional Personality Questionnaire scales. Journal of Personality and Social Psychology, 72, 929-938. doi: 10.1037/0022-3514.72.4.929

Friedman, H. S., Kern, M. L., Hampson, S. E., \& Duckworth, A. L. (2014). A new life-span approach to conscientiousness and health: Combining the pieces of the causal puzzle. Developmental Psychology, 50, 1377 1389. doi:10.1037/a0030373

Fujiwara, T., \& Kawachi, I. (2009). Is education causally related to better health? A twin fixed-effect study in the USA. International Journal of Epidemiology, 38, 1310-1322. doi:10.1093/ije/dyp226

Goldberg, L. R. (1993). The structure of phenotypic personality traits. American Psychologist, 48, 26-34. doi:10.1037/0003-066X.48.1.26

Harro, J., Merenäkk, L., Nordquist, N., Konstabel, K., Comasco, E., \& Oreland, L. (2009). Personality and the serotonin transporter gene: Associations in a longitudinal population-based study. Biological Psychology, 81, 9-13. doi:10.1016/j.biopsycho.2009.01.001

Hasin, D. S., Stinson, F. S., Ogburn, E., \& Grant, B. F. (2007). Prevalence, correlates, disability, and comorbidity of DSM-IV alcohol abuse and dependence in the United States. Archives of General Psychiatry, 64 830-842. doi:10.1001/archpsyc.64.7.830

Hicks, B. M., South, S. C., DiRago, A. C., Iacono, W. G., \& McGue, M. (2009). Environmental adversity and increasing genetic risk for externalizing disorders. Archives of General Psychiatry, 66, 640-648. doi: 10.1001/archgenpsychiatry.2008.554

Hopwood, C. J., Donnellan, M. B., Blonigen, D. M., Krueger, R. F., McGue, M., Iacono, W. G., \& Burt, S. Al. (2011). Genetic and environmental influences on personality trait stability and growth during the transition to adulthood: A three-wave longitudinal study. Journal of Personality and Social Psychology, 100, 545-556. doi:10.1037/ a0022409

Jang, K. L., Livesley, W. J., Angleitner, A., Riemann, R., \& Vernon, P. A. (2002). Genetic and environmental influences on the covariance of facets defining the domains of the five-factor model of personality. Personality and Individual Differences, 33, 83-101. doi:10.1016/S01918869(01)00137-4

Jang, K. L., Livesley, W. J., \& Vernon, P. A. (1996). Heritability of the Big Five personality dimensions and their facets: A twin study. Journal of Personality, 64, 577-592. doi:10.1111/j.1467-6494.1996.tb00522.x

Jang, K. L., McCrae, R. R., Angleitner, A., Riemann, R., \& Livesley, W. (1998). Heritability of facet-level traits in a cross-cultural twin sample: Support for a hierarchical model of personality. Journal of Personality 
and Social Psychology, 74, 1556-1565. doi:10.1037/0022-3514.74.6 .1556

Johnson, W., \& Krueger, R. F. (2004). Genetic and environmental structure of adjectives describing the domains of the Big Five Model of personality: A nationwide US twin study. Journal of Research in Personality, 38, 448-472. doi:10.1016/j.jrp.2003.11.001

Johnson, W., \& Krueger, R. F. (2005). Predictors of physical health: Toward an integrated model of genetic and environmental antecedents. The Journals of Gerontology, Series B: Psychological Sciences and Social Sciences, 60, 42-52. doi:10.1093/geronb/60.Special_Issue_1.42

Kandler, C., Bleidorn, W., Riemann, R., Spinath, F. M., Thiel, W., \& Angleitner, A. (2010). Sources of cumulative continuity in personality: A longitudinal multiple-rater twin study. Journal of Personality and Social Psychology, 98, 995-1008. doi:10.1037/a0019558

Kandler, C., Riemann, R., Spinath, F. M., \& Angleitner, A. (2010). Sources of variance in personality facets: A multiple-rater twin study of self-peer, peer-peer, and self-self (dis)agreement. Journal of Personality, 78, 1565-1594. doi:10.1111/j.1467-6494.2010.00661.x

Keller, M. C., Coventry, W. L., Heath, A. C., \& Martin, N. G. (2005). Widespread evidence for non-additive genetic variation in Cloninger's and Eysenck's personality dimensions using a twin plus sibling design. Behavior Genetics, 35, 707-721. doi:10.1007/s10519-005-6041-7

Kendler, K. S., Bulik, C. M., Silberg, J., Hettema, J. M., Myers, J., \& Prescott, C. A. (2000). Childhood sexual abuse and adult psychiatric and substance use disorders in women: An epidemiological and cotwin control analysis. Archives of General Psychiatry, 57, 953-959. doi: 10.1001/archpsyc.57.10.953

Kendler, K. S., Thornton, L. M., Gilman, S. E., \& Kessler, R. C. (2000). Sexual orientation in a national sample of twin and sibling pairs. American Journal of Psychiatry, 157, 1843-1846. doi:10.1176/appi.ajp.157 .11 .1843

Kern, M. L., Hampson, S. E., Goldberg, L. R., \& Friedman, H. S. (2014). Integrating prospective longitudinal data: Modeling personality and health in the Terman Life Cycle and Hawaii Longitudinal studies. Developmental Psychology, 50, 1390-1406. doi:10.1037/a0030874

Kessler, R. C., Gilman, S. E., Thornton, L. M., \& Kendler, K. S. (2004). Health, wellbeing, and social responsibility in the MIDUS twin and sibling subsamples. In O. G. Brim, C. D. Ryff, \& R. C. Kessler (Eds.), How healthy are we? A national study of wellbeing at midlife (pp. 124-152). Chicago, IL: University of Chicago Press.

Krueger, R. F. (2000). Phenotypic, genetic, and nonshared environmental parallels in the structure of personality: A view from the Multidimensional Personality Questionnaire. Journal of Personality and Social Psychology, 79, 1057-1067. doi:10.1037/0022-3514.79.6.1057

Krueger, R. F., Hicks, B. M., Patrick, C. J., Carlson, S. R., Iacono, W. G., \& McGue, M. (2002). Etiologic connections among substance dependence, antisocial behavior, and personality: Modeling the externalizing spectrum. Journal of Abnormal Psychology, 111, 411-424. doi:10.1037/ 0021-843X.111.3.411

Krueger, R. F., Markon, K. E., Patrick, C. J., Benning, S. D., \& Kramer, M. D. (2007). Linking antisocial behavior, substance use, and personality: An integrative quantitative model of the adult externalizing spectrum. Journal of Abnormal Psychology, 116, 645-666. doi:10.1037/ 0021-843X.116.4.645

Krueger, R. F., South, S. C., Johnson, W., \& Iacono, W. (2008). The heritability of personality is not always $50 \%$ : Gene-environment interactions and correlations between personality and parenting. Journal of Personality, 76, 1485-1522. doi:10.1111/j.1467-6494.2008.00529.x

Lachman, M., \& Weaver, S. L. (1997). The Midlife Development Inventory (MIDI) personality scales: Scale construction and scoring (Tech. Rep. No. 1). Waltham, MA: Brandeis University, Department of Psychology.

Li, M. D., Cheng, R., Ma, J. Z., \& Swan, G. E. (2003). A meta-analysis of estimated genetic and environmental effects on smoking behavior in male and female adult twins. Addiction, 98, 23-31. doi:10.1046/j.13600443.2003.00295.x

Loehlin, J. C., Neiderhiser, J. M., \& Reiss, D. (2003). The behavior genetics of personality and the NEAD study. Journal of Research in Personality, 37, 373-387. doi:10.1016/S0092-6566(03)00012-6

Loehlin, J. C., Willerman, L., \& Horn, J. M. (1987). Personality resemblance in adoptive families: A 10-year follow-up. Journal of Personality and Social Psychology, 53, 961-969. doi:10.1037/0022-3514.53.5.961

Luciano, M., Wainwright, M. A., Wright, M. J., \& Martin, N. G. (2006). The heritability of conscientiousness facets and their relationship to IQ and academic achievement. Personality and Individual Differences, 40 , 1189-1199. doi:10.1016/j.paid.2005.10.013

Luo, X., Kranzler, H. R., Zuo, L., Zhang, H., Wang, S., \& Gelernter, J. (2007). CHRM2 variation predisposes to personality traits of agreeableness and conscientiousness. Human Molecular Genetics, 16, 1557-1568. doi: $10.1093 / \mathrm{hmg} / \mathrm{ddm} 104$

Lykken, D. T., Bouchard, T. J., McGue, M., \& Tellegen, A. (1990). The Minnesota Twin Family Registry: Some initial findings. Acta Genetica Medica Gemellol, 39, 35-70.

Markon, K. E., \& Krueger, R. F. (2004). An empirical comparison of information-theoretic selection criteria for multivariate behavior genetic models. Behavior Genetics, 34, 593-610. doi:10.1007/s10519-004$5587-0$

Markon, K. E., Krueger, R. F., \& Watson, D. (2005). Delineating the structure of normal and abnormal personality: An integrative hierarchical approach. Journal of Personality and Social Psychology, 88, 139157. doi:10.1037/0022-3514.88.1.139

Martin, N. G., Eaves, L. J., Kearsey, M. J., \& Davies, P. T. (1978). The power of the classical twin study. Heredity, 40, 97-116. doi:10.1038/ hdy. 1978.10

McCrae, R. R., \& Costa, P. T., Jr. (2008). The five-factor theory of personality. In O. P. John, R. W. Robins, \& L. A. Pervin (Eds.), Handbook of personality psychology: Theory and research (3rd ed., pp. 159-181). New York, NY: Guilford Press.

McCrae, R. R., Scally, M., Terracciano, A., Abecasis, G. R., \& Costa, P. T. (2010). An alternative to the search for single polymorphisms: Toward molecular personality scales for the five-factor model. Journal of Personality and Social Psychology, 99, 1014-1024. doi:10.1037/a0020964

McGue, M., Bacon, S., \& Lykken, D. T. (1993). Personality stability and change in early adulthood: A behavioral genetic analysis. Developmental Psychology, 29, 96-109. doi:10.1037/0012-1649.29.1.96

McGue, M., \& Bouchard, T. J. (1984). Quality of twin data for the effects of age and sex. Behavior Genetics, 14, 325-343. doi:10.1007/ BF01080045

McGue, M., Osler, M., \& Christensen, K. (2010). Causal inference and observational research: The utility of twins. Perspectives on Psychological Science, 5, 546-556. doi:10.1177/1745691610383511

Middeldorp, C. M., de Moor, M. H. M., McGrath, L. M., Gordon, S. D., Blackwood, D. H., Costa, P. T., . . Boomsma, D. I. (2011). The genetic association between personality and major depression or bipolar disorder: A polygenic score analysis using genome-wide association data. Translational Psychiatry, 1, e50. doi:10.1038/tp.2011.45

Munafò, M. R., Brown, S. M., \& Hariri, A. R. (2008). Serotonin transporter (5-HTTLPR) genotype and amygdala activation: A meta-analysis. Biological Psychiatry, 63, 852-857. doi:10.1016/j.biopsych.2007.08.016

Munafò, M. R., Clark, T. G., Moore, L. R., Payne, E., Walton, R., \& Flint, J. (2003). Genetic polymorphisms and personality in healthy adults: A systematic review and meta-analysis. Molecular Psychiatry, 8, 471-484. doi:10.1038/sj.mp.4001326

Munafò, M. R., \& Flint, J. (2011). Dissecting the genetic architecture of human personality. Trends in Cognitive Sciences, 15, 395-400.

Munafò, M. R., Freimer, N. B., Ng, W., Ophoff, R., Veijola, J., Miettunen, J., . . Flint, J. (2009). 5-HTTLPR genotype and anxiety-related personality traits: A meta-analysis and new data. American Journal of 
Medical Genetics Part B: Neuropsychiatric Genetics, 150B, 271-281. doi:10.1002/ajmg.b.30808

Neale, M. C., Boker, S. M., Xie, G., \& Maes, H. H. (2003a). Mx: Statistical modeling. Richmond: Department of Psychiatry, VCU Box 900126, Richmond, VA 23298.

Neale, M. C., Boker, S. M., Xie, G., \& Maes, H. H. (2003b). Mx: Statistical modeling (6th ed.): Richmond: Department of Psychiatry, Virginia Commonwealth University.

Plomin, R., Corley, R., Caspi, A., Fulker, D. W., \& DeFries, J. C. (1998). Adoption results for self-reported personality: Evidence for nonadditive genetic effects? Journal of Personality and Social Psychology, 75, 211-218. doi:10.1037/0022-3514.75.1.211

Plomin, R., DeFries, J. C., McClearn, G. E., \& McGuffin, P. (2008). Behavioral genetics (5th ed.). New York, NY: Worth Publishers.

Purcell, S. (2002). Variance components models for gene-environment interaction in twin analysis. Twin Research, 5, 554-571.

Roberts, B. W., \& Bogg, T. (2004). A longitudinal study of the relationships between conscientiousness and the social-environmental factors and substance-use behaviors that influence health. Journal of Personality, 72, 325-354. doi:10.1111/j.0022-3506.2004.00264.x

Roberts, B. W., Kuncel, N., Shiner, R. N., Caspi, A., \& Goldberg, L. R. (2007). The power of personality: The comparative validity of personality traits, socio-economic status, and cognitive ability for predicting important life outcomes. Perspectives in Psychological Science, 2, 313345. doi:10.1111/j.1745-6916.2007.00047.x

Rosenberg, S., Templeton, A. R., Feigin, P. D., Lancet, D., Beckmann, J. S., Selig, S., . . Skorecki, K. (2006). The association of DNA sequence variation at the MAOA genetic locus with quantitative behavioural traits in normal males. Human Genetics, 120, 447-459. doi: 10.1007/s00439-006-0198-x

Sadler, M. E., Miller, C. J., Christensen, K., \& McGue, M. (2011). Subjective wellbeing and longevity: A co-twin control study. Twin Research and Human Genetics, 14, 249-256. doi:10.1375/twin.14.3.249

Shanahan, M. J., Hill, P. L., Roberts, B. W., Eccles, J., \& Friedman, H. S. (2014). Conscientiousness, health, and aging: The life course of personality model. Developmental Psychology, 50, 1407-1425. doi: 10.1037/a0031130

South, S. C., \& Krueger, R. F. (2008). Marital quality moderates genetic and environmental influences on the internalizing spectrum. Journal of Abnormal Psychology, 117, 826-837. doi:10.1037/a0013499
South, S. C., \& Krueger, R. F. (2011). Genetic and environmental influences on internalizing psychopathology vary as a function of economic status. Psychological Medicine, 41, 107-117. doi:10.1017/ S0033291710000279

South, S. C., Krueger, R. F., Johnson, W., \& Iacono, W. G. (2008). Adolescent personality moderates genetic and environmental influences on relationships with parents. Journal of Personality and Social Psychology, 94, 899-912. doi:10.1037/0022-3514.94.5.899

Svedberg, P., Lichtenstein, P., \& Pedersen, N. L. (2001). Age and sex differences in genetic and environmental factors for self-rated health: A twin study. Journal of Gerontology: Social Sciences, 56, S171-S178. doi:10.1093/geronb/56.3.S171

Tellegen, A., Lykken, D. T., Bouchard, T. J., Wilcox, K. J., Segal, N. L., \& Stephen, R. (1988). Personality similarity in twins reared apart and together. Journal of Personality and Social Psychology, 54, 1031-1039. doi:10.1037/0022-3514.54.6.1031

Tellegen, A., \& Waller, N. G. (in press). Exploring personality through test construction: Development of the Multidimensional Personality Questionnaire $(M P Q)$ : Minneapolis: University of Minnesota Press.

Visscher, P. M., Brown, M. A., McCarthy, M. I., \& Yang, J. (2012). Five years of GWAS discovery. American Journal of Human Genetics, 90 , 7-24. doi:10.1016/j.ajhg.2011.11.029

World Health Organization. (2002). The world health report 2002: Reducing risks, promoting healthy life. Geneva, Switzerland: Author.

Yamagata, S., Suzuki, A., Ando, J., Ono, Y., Kijima, N., Yoshimura, K., . . Jang, K. L. (2006). Is the genetic structure of human personality universal? A cross-cultural twin study from North America, Europe, and Asia. Journal of Personality and Social Psychology, 90, 987-998. doi: 10.1037/0022-3514.90.6.987

Young-Wolff, K. C., Enoch, M.-A., \& Prescott, C. A. (2011). The influence of gene-environment interactions on alcohol consumption and alcohol use disorders: A comprehensive review. Clinical Psychology Review, 31, 800-816. doi:10.1016/j.cpr.2011.03.005

Zuo, L., Gelernter, J., Kranzler, H. R., Stein, M. B., Zhang, H., Wei, F., . . . Luo, X. (2010). ADH1A variation predisposes to personality traits and substance dependence. American Journal of Medicine Genetics Part B: Neuropsychiatric Genetics, 153B, 376-386.

Received February 19, 2012

Revision received July 11, 2012

Accepted August 14, 2012 